\title{
POPUlisMOS, Auge De la Extrema Derecha Y Crisis De LA DEMOCRACIA LIBERAL
}

El tiempo pervertido: derecha e irquierda en el siglo XXI. Esteban Hernández, Akal, Madrid, 2018.

Las nuevas caras de la derecha. Enzo Traverso, Siglo XXI, Buenos Aires, 2018.

El pueblo contra la democracia: Por qué nuestra libertad está en peligro y cómo salvarla. Yascha Mounk, Paidós, Barcelona, 2018.

\section{Carlos Zeller ${ }^{1}$}

Las elecciones parlamentarias celebradas el pasado 28 de abril en España confirmaron la significativa entrada del partido de extrema derecha, VOX, en el Parlamento con el 10\% del voto

\footnotetext{
${ }^{1}$ Miembro del Observatori del Conflicte Social, Universitat de Barcelona. czellerorellana@gmail.com
} 
emitido y 24 parlamentarios en el Congreso Nacional. Y ocurrió algo mucho más importante: este partido mostró una capacidad para enmarcar globalmente aspectos significativos de la contienda política y condicionar aspectos sustantivos de la acción de otros actores de la derecha política española. Este nuevo actor político intenta abiertamente romper algunos de los diques construidos por la cultura política tradicional - por ejemplo, apela a clausurar medios de comunicación sin complejo, revindica prácticas casi inexistentes en España como el "derecho" a portar armas, descalifica la lucha contra la violencia de género, hace planteamientos xenófobos, desconoce y desafía abiertamente los límites y contrapesos que impone el sistema democrático- y naturaliza prácticas comunicativas que transforman radicalmente los procesos tradicionales de formación de la opinión pública política.

La mentira y el engaño devienen, así, un instrumento como cualquier otro de comunicación pública, se introducen conceptos prepolíticos, o de difícil encaje en la cultura democrática tal y como han sido usados, tales como la categoría "pueblo", "mandato democrático", y todo aquello que contribuye a construir una identidad inamovible y única, por encima de divisiones de clase, condición social o estatus. El auge de este partido político en España - con un proceso comparativamente breve, aunque sus matrices ideológicas estuviesen larvadas en el sistema político y en la sociedad española - se inserta en un movimiento de largo alcance en Europa y, en particular, en la 
Unión Europea. Todos estos movimientos se atribuyen (en régimen de monopolio) la capacidad de definir el "amor a la patria", de nombrar a los auténticos miembros de la "sociedad sana" o, en el lado opuesto, en señalar a los enemigos interiores o exteriores de la nación. Y sobre este eje articula una estrategia de comunicación política e institucional que pivota sobre la noción de reconocimiento de la autenticidad del ser nacional y de la fundación de un "nuevo nosotros". Los nombres de algunas organizaciones y partidos son significativos al respecto: Verdaderos Finlandeses, Partido de la Libertad en Austria, o Amanecer Dorado en Grecia. Representan el viaje que va desde las esencias nacionales y de patria hasta el nihilismo absoluto que cierra todo espacio de deliberación. En la mayoría de casos, los discursos se replican en diferentes países y promueven idénticos resultados: apelan a los auténticos daneses, o finlandeses, o suecos, o españoles; o al orgullo de ser francés, danés, español, etc.; y confluyen en la "defensa de lo propio", tal como lo expresan, por ejemplo, Alternativa para Alemania o América Primero.

Mediante estos discursos, estas organizaciones ofrecen a las clases desfavorecidas una oferta simbólica de algo sólido no evanescente (o algo a lo que agarrarse en medio de las incertidumbres económicas) con el que contrarrestar unas cuantas y potentes certezas sobre su situación negativa y real: la precarización de la vida, la ruptura del pacto social, la expansión desenfrenada de zonas de inseguridad social, la sensación de 
formar parte de los perdedores que se traduce en miedos y en respuestas anómicas, etc. Evidentemente, lo que ofrecen no altera los patrones de distribución del ingreso y no modifica nada estructural en relación a las desigualdades ${ }^{2}$, ni a la recuperación de un pasado de bienestar al que se mira como país añorado. Al contrario, en la mayoría de casos, como muestran las experiencias de gobiernos autoritarios en distintos países (Estados Unidos, Hungría, Polonia, pero también en países en los que la extrema derecha participa como fuerza de gobierno minoritaria) la orientación de la política pública reproduce la lógica económica que crea las desigualdades, la misma lógica que ha desplazado a una parte significativa de la población a un lugar de máxima inseguridad social. Y este es precisamente el enigma: ¿por qué surgen apoyos desde los sectores precarizados para el ascenso de estas opciones políticas cuando sus promesas son desmentidas por los hechos?

La filósofa y ensayista húngara Agnes Heller señaló: "Hoy, en muchos lugares del mundo, los mismos tiranos son elegidos y reelegidos por la mayoría."” También se preguntó: "Si los tiranos pueden ser elegidos una y otra vez por la mayoría; si la riqueza se redistribuye a la inversa, ¿Qué es lo que mueve a la gente? Pregunta sobre la que concluyó con una respuesta aparentemente

2 Este supuesto "reconocimiento" de los problemas que padecen los "ciudadanos de a pie" explica en parte la similitud programática que se da entre organizaciones de extrema derecha y alternativas de izquierda radical, tal y como ocurre en Francia o Alemania.

3 “La Tiranía que crece en el corazón de Europa”, Agnes Heller. El País, 21-IV-2019. 
simple: "la ideología combinadas con las políticas de la identidad". Su esquema de reflexión trasladado al presente se traduce en el "reconocimiento" que las nuevas opciones políticas parecen ofrecer creando el simulacro de un espacio de reparación histórica para los grupos sociales que han resultado perdedores de la globalización.

Una idea similar a la de Heller es la que expresa ahora el filósofo político Jean Claude Michéa, pero focalizando su atención en el elitismo - real o supuesto- de la llamada izquierda liberal ${ }^{4}$. Este autor francés alude al desdén con que, a su juicio, esta izquierda trata a los valores y a las demandas que han venido de las clases populares, especialmente desde que éstas le han retirado su apoyo en las contiendas electorales. Alude al impacto social y emocional que sobre las clases populares han podido tener algunas formas discursivas propias de las acciones colectivas protagonizadas por la clase media urbana. En concreto, una pancarta de las protestas de los estudiantes en Francia en 2016 decía: "Por menos de 1.200 euros, ¡no me levanto!”. Y Michéa se pregunta ¿qué recepción y descodificación cultural pueden tener estos enunciados entre los grupos sociales precarizados que no tienen elección, es decir, entre las personas más modestas, condenadas a realizar cualquier trabajo y el peor pagado? El autor señala que "los que no tienen otra opción que levantarse cada mañana" es muy probable que el eslogan de la protesta lo "lean"

\footnotetext{
${ }^{4}$ Ver Notre ennemi, le capital. Jean Claude Michéa, Flammarion, París, 2017 (páginas 19-26 y 73-77)
} 
como una afrenta y es, por tanto, muy probable que esta lectura haya abierto una fosa profunda entre los grupos que supuestamente conforman la llamada izquierda social. Afirma, además, que esto no tiene nada de anécdota particular, al contrario, constituye un patrón de comportamiento erróneo dominante en la izquierda liberal. Sobre la base de estas afrentas y desprecios es, a juicio del autor, por donde crece en Francia el Frente Nacional desde abajo. En realidad, creemos que podemos rastrear muchos ejemplos similares con los que, en distintos contextos y países, se ha ido fijando un marco de acción colectiva que, más que contribuir a la unión, profundiza la actual segmentación de la izquierda social.

Una semana antes de las elecciones en España, en Finlandia el partido de extrema derecha, Verdaderos Finlandeses, prácticamente obtuvo el mismo porcentaje de votos y un escaño menos que el partido ganador socialdemócrata. Se trata de un nodo más de una cadena que se remonta al menos hasta 2013, y que parece conformar un nuevo ciclo político. Filipinas, Hungría, Italia, Estados Unidos, Brasil, entre otros muchos países y regiones, conforman una geografía política peculiar con liderazgos de carácter autoritario (un liderazgo de "hombres fuertes", el "bloque del odio" en palabras de Sami Naïr) que ya tiene un esbozo de coordinación global. Su acceso a las instituciones y a algunos resortes de poder institucional es un hecho establecido, como lo es su capacidad para orientar aspectos 
claves de la formación de la opinión pública en sus respectivos países.

En el epicentro temporal de la Gran Recesión, avanzada la década de 2010, emergió con fuerza una preocupación política sobre la crisis de la democracia. Los indicios eran múltiples y de muy diferente entidad. Algunos parecían novedosos, consecuencias más o menos directas de la crisis económica en marcha o de cambios tecnológicos y culturales introducidos por las nuevas tecnologías de comunicación digital; pero otros expresaban tendencias fuertes que estaban ya ancladas en la evolución política y cultural de las sociedades de capitalismo avanzado. La irrupción de partidos de extrema derecha con vocación mayoritaria, más allá de la experiencia francesa que se remonta a más de 15 años atrás, ha sido el indicador avanzado de alerta sobre la actual crisis de la democracia.

Los tres libros que comentamos aquí ofrecen análisis e información útil e interesante para acercarnos a esta crisis de la democracia liberal. Los autores tienen perspectivas metodológicas diferentes y revisan los hechos sociales desde puntos de observación muy particulares. Pero todos contribuyen a hacer un poco más inteligible esta difícil encrucijada por la que atraviesan los sistemas democráticos al completo, y la política de izquierdas y sus condiciones de futuro, de manera particular.

\section{Los pueblos eligen, los mercados deciden}


El tiempo pervertido: derecha e izquierda en el siglo XXI. Esteban Hernández, Akal, Madrid, 2018.

Esteban Hernández compone su libro con materiales de la actualidad más contingente e inmediata, pero los hechos a los que se refiere están enmarcados en una perspectiva histórica que abarca las últimas cuatro décadas. Aborda, además, temas generales como la irrupción del neoliberalismo, las "doctrinas del shocks" y la globalización económica. Los análisis propuestos adoptan en muchos casos el formato de una crónica narrativa (al estilo de los excelentes artículos que va publicando en el periódico digital, El Confidencial) pero que apuntan con lucidez a mostrar cuáles son las tendencias fuertes que están presentes en los cambios sociales que hay en marcha. Todo el libro se organiza sobre la variable del tiempo histórico en el que se conforma la contingencia política actual. El autor no desdeña en ningún momento, además, tratar sobre la relevancia de las divisiones izquierda/derecha, así como la especificidad cultural y política de cada una de estas opciones. Pero sitúa el análisis de ambas opciones en un marco en el que éstas se ven confrontadas a límites que reducen al extremo las posibilidades de acción diferenciada, al menos en el terreno de los equilibrios básicos de la economía y la distribución.

La convergencia fáctica que se ha dado entre "progresistas" y "conservadores", la necesidad de mantener los equilibrios políticos para no alterar las nuevas pautas distributivas, 
los intentos de no desafiar la orientación dada por los organismos multilaterales investidos de autoridad son, entre otros factores, los elementos que constituyen el trasfondo que, a juicio de Esteban Hernández, propicia que los partidos que compiten en el mercado electoral desplacen discursivamente sus diferencias hacia las cuestiones culturales. Este es el terreno en el cual el eje conservador/progresista conserva aún una graduación que hace posible la diferencia entre sus extremos, aunque es de valor simbólico. Según Hernández, "Cuanto más de acuerdo estaban [progresistas y conservadores] en los asuntos económicos, más tensión provocaban en lo simbólico".

Los cambios económicos y en la organización del trabajo operados en las últimas décadas enmarcan buena parte del análisis de Hernández sobre la tensión política izquierda-derecha y sus efectos desdemocratizadores sobre las sociedades europeas y las democracias liberales en general. La idea de que, ante el vaciado de contenido y significado de los aspectos formales de la democracia liberal, las distintas opciones políticas muestran la misma impotencia para gobernar la "división del trabajo" entre pueblos y ciudadanía, por una parte, y mercados, por otra ${ }^{5}$. Sobre este aspecto, Esteban Hernández señala, además, una reciente evolución: "Hasta la fecha, la estabilidad del sistema se sostenía en gran parte en la idea de que no había alternativa, pero la

\footnotetext{
${ }^{5}$ Situación descrita por Wolfgang Streeck con la figura de "dos soberanos" en "Mercados y Pueblos: capitalismo democrático e integración europea" en New Left Review $\mathrm{n}^{\circ}$ 73, Madrid, 2012.
} 
aparición de los populismos de derecha ha quebrado esa convicción. La puerta se ha abierto y los votantes saben ya que otro mundo es posible, aunque pueda ser peor". Este libro puede ayudar a entrever por dónde ha discurrido este cambio social reciente.

\section{Populismos y radicalización de la derecha}

Las nuevas caras de la derecha. Enzo Traverso, Siglo XXI, Buenos Aires, 2018.

El historiador italiano hace una revisión muy detallada de la evolución de las derechas en Europa y otras zonas en las que funciona el llamado capitalismo democrático.

El texto está organizado en forma de entrevista/conversación entre su autor y Regis Meyran, y revisa la evolución de las derechas abordando cuestiones políticas, económicas, geoestratégicas y culturales, al mismo tiempo que refiere algunos conceptos clave clásicos y propone otros nuevos para caracterizar la evolución política del presente.

En el primer capítulo, “¿Del fascismo al postfascismo?”, Traverso toma distancia -igual que hizo en su momento Agnes Heller en relación al régimen imperante en Hungría- de la calificación "fascista" cuando esta es aplicada sin matices a los actuales movimientos de extrema derecha. Afirma que hoy esta caracterización es "más un obstáculo que un elemento esclarecedor del debate", que poco facilita entender lo que 
realmente se está produciendo. Propone utilizar el término postfascismo, relativamente más neutro, dado que no alude directamente a fenómenos históricos concretos del pasado, ni a los rasgos y contextos únicos del pasado, aunque en el presente se puedan dar elementos que los recuerdan. Según este autor, la irrupción de las extremas derechas y la reconfiguración de las derechas radicales a escala global es un proceso aún en curso que no ha acabado de cristalizar y, en ese sentido, resulta más útil conceptualizarlo de forma provisoria y tentativa. También argumenta sobre las peculiaridades y especificidades que exhibe este fenómeno en los distintos países en que se manifiesta. Aunque reconoce una matriz originaria que liga entre sí a la mayoría de estos movimientos y que, de hecho, también los conecta en algún grado con experiencias históricas propias del fascismo, prefiere remarcar sus especificidades: se dan en el inicio del siglo XXI (nada que ver con el tiempo histórico del siglo anterior) y tienen un contenido ideológico impreciso y contradictorio que debemos aclarar.

Traverso advierte también que si el postfascismo logra llegar al poder en un país central como es Francia, es fácil que éste se transforme en un "neofascismo", con posibilidad real de irradiar su evolución en el conjunto del campo de las derechas. En la misma dirección, nos llama la atención sobre los efectos potencialmente disgregadores que podrá tener la llegada al poder del Frente Nacional en Francia sobre la existencia misma de la UE. Sin embargo, reconoce que, hoy por hoy, las nuevas 
derechas radicales (más allá de sus continuos y, en algún caso, espectaculares avances) no tienen todavía el favor de las élites económicas globales, aunque es plausible pensar que eso pueda suceder ${ }^{6}$. El autor recuerda en este sentido, aunque marcando la distancia necesaria con el presente, el momento histórico en el que los nazis pasaron a convertirse en interlocutores del capitalismo industrial y financiero en Alemania.

Otro de sus ejes de la reflexión es, a su juicio, la necesidad de precisar las condiciones en las que se extiende una visión populista generalizada. Utiliza como dato de análisis las ideas fuerza que sustentan el tratamiento periodístico dado (desde los grandes periódicos europeos) a los avatares de la contienda política y al nuevo rol adoptado por las derechas radicales en Europa. La crítica principal es la conversión de la categoría populismo en una especie de fenómeno "ómnibus" contenedor al mismo tiempo de una cosa y de la contraria (por ejemplo, contenedor de la promoción de xenofobia al mismo tiempo que se afirma la crítica a la orientación de la política económica

\footnotetext{
${ }^{6}$ Esto es un aspecto clave para caracterizar el redespliegue de las derechas radicales y de la crisis de la democracia liberal. Algunos observadores caracterizan los populismos de extrema derecha como un momento de crisis en las élites globales y en el sistema de hegemonía global. Un aspecto que Esteban Hernández también aborda señalando las connotaciones hegemónicas que tiene el impulso dado a estas derechas radicales en Europa desde la actual administración estadounidense. W. Streeck, por su parte, sitúa plenamente el análisis del despliegue de las derechas radicales en la UE en el marco de la transición de hegemonía en que está inmerso el capitalismo y el sistema global ("un imperio europeo en vías de colapso", en Le Monde Diplomatique, mayo de 2019).
} 
existente). Traverso resalta el carácter de "arma de combate político" que tiene hoy día la expresión populista o populismo, tal y como están siendo utilizados.

Democracia frente a la voluntad popular o como reinventar la ciudadanía democrática

El pueblo contra la democracia: Por qué nuestra libertad está en peligro y cómo salvarla. Yascha Mounk, Paidós, Barcelona, 2018.

El trabajo de Yascha Mounk, profesor en la Universidad de Harvard, sociólogo político, periodista y director del Instituto Tony Blair para el Cambio Global, es una aportación muy valiosa para comprender la actual encrucijada de la democracia y su evolución. Es un libro documentado, que revisa una gran diversidad de experiencias y situaciones, con un horizonte temporal que fundamentalmente se inicia en los inicios de la Gran Recesión.

Escrito con una narrativa ágil, el trabajo de Mounk se beneficia de sus observaciones directas en distintos lugares de Europa. Un observador privilegiado de coyunturas críticas protagonizadas por la irrupción de las extremas derechas como actor del campo político en distintos países y por la novedosa capacidad mostrada para incidir en los procesos de formación de la opinión pública por la doble vía de instalar en el debate público visiones consideradas (hasta hace poquísimo tiempo) políticamente incorrectas, mediante una hábil estrategia de 
comunicación pública desde las redes sociales. Es una estrategia que funde eficazmente tradición y modernidad.

El libro se organiza en tres partes que revisan la crisis de la democracia liberal, sus orígenes y la estrategia para remediarla. En la primera parte, se hace una revisión conceptual y se incide en la caracterización más precisa de los fenómenos populistas y de las nuevas derechas. Toma distancia de la caracterización de fascismo o neofascismo, argumentando que las prácticas políticas observables -al menos hasta ahora- siguen apelando a las formas democráticas y a la construcción de una voluntad política. Distingue entre democracia liberal, democracia iliberal (Polonia y Hungría serían ejemplos tipo de esta última) y liberalismo no democrático (como es la gestión política que se hace desde la Unión Europea). Mounk destaca que los actuales movimientos de extrema derecha no defienden la abolición de la democracia, sino construir una nueva voluntad popular capaz de remodelar la sociedad. De alguna manera, estos movimientos serían articuladores de la voz de quienes se han visto privados de ella (de ahí que una idea fuerza de sus campañas electorales es precisamente la voluntad de dar la palabra al pueblo, de recibir y cumplir "los mandatos democráticos" que emanan del pueblo). El autor reconoce que esta estrategia puede obedecer simplemente a consideraciones electorales, para buscar y ocupar un espacio social que ha sido abandonado por el resto de partidos en las democracias liberales. Incluyen una supuesta defensa de una forma de "democracia directa", presente en los programas 
políticos con sus propuestas de convocar referéndums para resolver cuestiones críticas y sensibles que ocupan la opinión pública: cuestiones como son qué estatus han de tener los inmigrantes residentes en un país, o la posibilidad o necesidad de bunkerizar fronteras, o la posibilidad o necesidad de modificar el sistema penal, o la posibilidad o necesidad de restringir la libertad religiosa, etc.

Mounk apela a comprender la "energía democrática" que subyace en la acción política de estas extremas derechas al mismo tiempo que alerta de la incompatibilidad de estas prácticas con el mantenimiento de las formas democráticas básicas. Este es el dilema que sintetiza el título del libro. Quizá uno de los problemas de este enfoque es que el carácter autoritario de los nuevos liderazgos no se valora suficientemente como riesgo para la supervivencia de la democracia, especialmente por su capacidad para inducir dinámicas de opinión con impactos de largo plazo en los sistemas de valores de la población. La construcción social de un enemigo catalizador de las pulsiones que emanan de una insatisfacción colectiva, de miedos e inseguridad gestados en la constatación de impotencias institucionales, colectivas y personales pueden tener -están teniendo- no sólo efectos desdemocratizadores, sino una perversión drástica de la democracia (la que hasta ahora hemos conocido) que conlleve la 
irrupción (no de una fórmula de postdemocracia) sino de un neofascismo abierto ${ }^{7}$.

A pesar de que el punto de observación del análisis de Mounk no coincide con los otros dos autores, dado que es propiamente liberal cuando señala que los problemas no resueltos (o mal resueltos) por el capitalismo en relación con la democracia no hace de estos dos sistemas algo incompatible, en conjunto, la lectura de los tres textos aportan una idea central y común: la necesidad de abordar la cuestión de la irrupción de las extremas derechas pasa por atacar directamente la desigualdad social y esto exige reconstruir un nuevo pacto social, probablemente desde un marco espacial e institucional que vaya más allá de los Estadosnación.

7 La caracterización de estos movimientos de extrema derecha como neofascismo está presente en varios analistas políticos. Sami Naïr, por ejemplo, sostiene abiertamente que nos encontramos ante una coyuntura histórica y caracteriza abiertamente como neo fascismo estos movimientos, aludiendo a rasgos históricos y características nuevas: "Es el proyecto de una sociedad jerarquizada de señores y siervos[...] de sumisión a un líder [...] una ideología que genera en la identidad de sus seguidores una potente liberación de instintos agresivos y hace estallar los tabús que limitan expresiones primitivas, violentas, en las relaciones sociales" ("Como frenar el nacional populismo", El País, 9-XII- 2018). 